https://doi.org/10.48009/2_iis_2008_95-102

\title{
MEASURING STUDENTS PERCEPTIONS OF BLACKBOARD USING THE TECHNOLOGY ACCEPTANCE MODEL: A PLS APPROACH
}

\author{
Leila Halawi, American University of Dubai, drhalawi@gmail.com \\ Richard McCarthy, Quinnipiac University, Richard.mccarthy@quinnipiac.edu
}

\begin{abstract}
In this study, partial least square approach (PLS) is applied to investigate the determinants of students' perceived usage results in the framework of university online or hybrid courses. A total of 134 valid responses from students who have finished or are currently enrolled in at least one online or hybrid course at two universities were employed to inspect the structural model. Using a structure that is in theory grounded in the technology acceptance model (TAM) and tested through TAM, the analysis of results suggest that separate factors guide the students' usage choice.
\end{abstract}

Keywords: distance education, E-learning, Blackboard, Technology acceptance model (TAM).

\section{INTRODUCTION}

The speedy growth of the Internet and growing software capabilities are affecting dynamics of teaching and learning in countless distinctive degrees. Online learning, web learning or elearning has developed into a central component of education schemes in the very last decade [27][15]. There has been striking developments in the platforms and systems that support online delivery [13][19].

The landscape of distance education is changing. This revolution is being pushed by the rising acceptance and popularity of online course offerings. Web-based education tools offer integrated environments of mixed technologies to assist varied educators and learners through the Internet [29]. Web-based education tools are continuously being re-designed by the developers to advance their usefulness and value.

The main objective of this research paper is to explain the student perceptions of Blackboard usage by employing the technology acceptance model (TAM). Our concern is to inspect whether the students view blackboard as indispensable, effective, and useful practicable tool in supporting their learning and whether their perceptions are linked to Blackboard usage.

This article adopts the subsequent structure. We start with a depiction of the theoretical foundations of this research. To elaborate, we first discuss web-based instruction and Elearning. We follow this by an explanation of the technology acceptance model (TAM). Next we present our methodology and results. The article wraps up with a discussion of the results in addition to the research implications of this contribution.

\section{WEB LEARNING AND BLACKBOARD}

Robust forces are driving business schools to adopt inventive instructional tools or technologies [12]. E-learning is frequently portrayed as encompassing the ability to surmount the location and time restrictions of the conventional face-to-face teaching techniques, and several researchers have quoted its value in improving the experience of the learning setting [26][2][18]

E-learning involves the use of the Internet and further associated information technologies to produce practices that support and maintain the advancement of education [4].

Online technologies are altering the students' learning style inside and outside of the classroom. A hybrid course presents instructors and learners with face-to-face lectures and technology enabled interface meant for clarifications, small group discussions, presentations and personalized support.

Computer mediated communication tools, such as Blackboard, allow institutions to expand their access to students who may not have the chance to attend classes physically due to either life or work issues. Blackboard system was the main system of the research. Blackboard system is a web-based thorough class management system available using the internet [16]. Blackboard was developed by faculty members at Cornell University as a course management system for 
education. The platform has been enhanced visibly. Blackboard is one of the main market leaders for Virtual Learning Environments. Blackboard helps create a virtual place or classroom where a community develops and interaction between students and their instructors is achieved through the use of discussion forums, e-mail, chat rooms and other functions. Blackboard highlights functions that help student and instructor learning outcomes. Learners usually employ the system to confirm or verify class assignment or announcement, connect with their colleagues or instructors and check their scores and evaluations. They can as well employ the system to retrieve course resources or take an examination.

For the purpose of this study, the term web learning will denote the use of Blackboard in hybrid classes and online classes in ways to supplement or substitute the regular lecture.

\section{TECHNOLOGY ACCEPTANCE MODEL (TAM) AND MODIFIED TECHNOLOGY ACCEPTANCE MODEL (TAM2)}

Davis [8] initially devised the technology acceptance model (TAM) to explicate computerusage behavior. The technology acceptance research area derives from various frameworks incorporating those developed in social psychology, learning theory, organizational dynamics, and decision making literature. TAM posits that perceived usefulness (PU) and perceived ease of use (PEOU) are critical factors in revealing information systems (IS) use.

TAM has attracted a mounting body of research and has gained empirical support explaining about 40 percent of the variance in behavioral intention and 30 percent of systems usage [23]. TAM has been extensively employed to forecast the acceptance of information technology systems [21].

The technology acceptance model (TAM) $[7,8]$ is a adaptation of the theory of reasoned action (TRA) $[1,7,8]$. TAM utilizes a beliefs-attitude intentions model that foresees technology acceptance by evaluating behavioral intentions by means of two belief constructs: (PU) and (PEOU). He outlined the former as "the degree to which a person believes that using a particular system would enhance his or her job performance" and the second as "the degree to which a person believes that using a particular system would be free of effort" [8, p320]. In its original version, TAM consists of the following constructs: PU, PEOU, attitude towards using, behavioral intention to use and actual use.

Earlier research attempted to include theoretical constructs to the original TAM from other theories proposed such as Task Technology Fit model (TFF) [11], flow theory [24] or innovation and diffusion theory (IDT) [17]. In TAM research, external variables such as system features [9] as well have been hypothesized to improve the explanatory and predictive power of TAM.

Venkatesh and Davis [32] extended the original TAM model to describe perceived usefulness and usage intentions in terms of social influence subjective norm, voluntariness, and image), and cognitive instrumental processes (job relevance, output quality, and result demonstrability). The extended model is known at present as TAM2 .It was tested using longitudinal data in both voluntary and mandatory settings. TAM2 increased the variance in perceived usefulness up to 60 percent and accounted for $34-52$ percent of the variance in intention to use [31]

TAM 2 has 2 versions: one concerning preimplementation beliefs about usefulness and ease of use and the other involving post implementation beliefs about usefulness and ease of use. The additional noteworthy distinction between the original and revised TAM models is the absence of attitude construct [30].

TAM2 has been applied to examine end-user acceptance of embracing a mixture of information technology systems. TAM2 has been employed to explain and forecast technology use in diverse disciplines such as decisions sciences, management sciences, information technology and management information systems. TAM2 has also been employed to estimate technology acceptance across many varied cultures. 
Figure 1 - TAM with External Variables TAM2

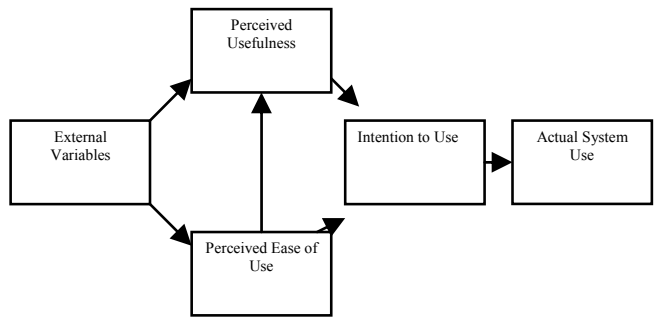

Academic institutions are allocating considerable amount of money, resources and time into web enhanced teaching in the conviction that adding up Web matter to a class improves the education experience for students. In addition, the success of comparable institutions in online adaptable education, have led officials to reassess online or hybrid alternatives as strategy to boost enrollments and revenues.

Conversely, little is known about the students' perceptions to use these new technologies.

Understanding factors related to students and in particular Blackboard perceptions and behavioral intentions might support the decisions and distribution of funds for computer mediated communications technologies that comprise the most positive financial return [28].

\section{RESEARCH QUESTIONS}

This research seeks to answer the following question: 1) Is there a relationship between the students perceptions of perceived usefulness, perceived ease of use, perceived usage and actual usage of Blackboard?

\section{METHODOLOGY}

\section{Research Method and Data Collection}

The study sample is comprised of undergraduate and graduate students at a southeastern, private university and northeastern private university. Both universities use Blackboard. Two hundred surveys were distributed. Only one hundred thirty three students MIS completed the questionnaire. The sample consisted of $63.2 \%$ males and $36.8 \%$ females. The survey instrument was administered in the classroom thereby providing a response rate of $66.5 \%$.

\section{Operationalization of Constructs}

To investigate the perceptions of the students towards the use of Blackboard, we used a questionnaire developed by Landry [20]. The instrument was initially proposed to examine student's estimation of effectiveness and implications of each of 10 course rudiments representing Blackboard. These fundamentals included: announcements, course documents, discussion boards, e-mail, external web-sites, faculty information, lectures, quizzes, and students tools and grades, and syllabus. Perceived usage construct consisted of 10 questions. Perceived Usefulness used two sets of 10 questions; one measuring perceived effectiveness and an additional measuring the perceived importance. Ease of use construct was operationalized using 2 questions. All questions used a five point Likert-type scale.

TAM2 hypothesize that behavioral intentions are a considerable determinant of actual system use, and behavioral intention is revealed by two main views perceived usefulness and perceived ease of use. Additionally, perceived ease of use is a determinant of perceived usefulness.

We tested the relationships between external variables (level of education, and gender), TAM belief constructs (PU and PEOU) and Blackboard usage.

\section{Instrument Validation}

To complete our analysis, we applied a Partial Least Squares and structural equation modeling (SEM) tool (Smart-PLS 2.0 M3). SEM permits a simultaneous assessment of the structural component (path model) and measurement component (factor model) in the one model.

Similar to LISREL and associated structural equation approaches, PLS presents the benefit of permitting the complete research model to be tested just once.

The measurement model consists of relationships among the conceptual factors of interests and the measures underlying each construct. The data indicates that the measures are robust in terms of their internal consistency reliability as indexed by the composite reliability (table 1). The composite reliabilities of the different measures ranged from 0.746 to 0.86 which exceed the recommended threshold value of 0.70 [25]. 
Table 1 Composite Reliability

\begin{tabular}{|l|l|}
\hline & Composite Reliability \\
\hline Actual Use & 0.861875 \\
\hline PEOU & 0.845933 \\
\hline PU & 0.854494 \\
\hline Perceived Usage & 0.746191 \\
\hline
\end{tabular}

Convergent validity measures the degree to which items on a scale are in theory linked. A common rule-of-thumb is a loading greater than 0.7 [6]. In the outer model, it is necessary to observe the loading column. In this case, all items loaded on their constructs from 0.71 to 0.86 indicating convergent validity.

We tested discriminant validity by exploring the average variance shared between a construct and its measures (AVE). Fornell and Larcker [14] recommend values higher than 0.50. Each element in the principal diagonal are always higher than off-diagonal elements in their corresponding row and column (table 2). The pattern supports our scales'discriminant validity, as the components in the main diagonal are constantly higher than the off-diagonal components in their equivalent row and column.

\section{Table 2 Latent Variable Correlations}

\begin{tabular}{|l|l|l|l|l|}
\hline & Actual Use & PEOU & PU & $\begin{array}{l}\text { Perceived } \\
\text { Usage }\end{array}$ \\
\hline Actual Use & $\mathbf{0 . 7 8 1 2 5}$ & & & \\
\hline PEOU & 0.782200 & $\mathbf{0 . 8 5 6 1 6}$ & & \\
\hline PU & 0.542375 & 0.479580 & $\mathbf{0 . 7 3 5 6 9}$ & \\
\hline $\begin{array}{l}\text { Perceived } \\
\text { Usage }\end{array}$ & 0.459648 & 0.407210 & 0.625916 & $\mathbf{0 . 7 7 1 5}$ \\
\hline
\end{tabular}

In the inner model, we have to observe the AVE index. Each AVE exceeds the 0.5 guideline as suggested (table 3 ).

Table 3 AVE

\begin{tabular}{|l|l|}
\hline & AVE \\
\hline Actual Use & 0.610352 \\
\hline PEOU & 0.733014 \\
\hline PU & 0.541254 \\
\hline Perceived Usage & 0.595196 \\
\hline
\end{tabular}




\section{RESULTS}

Blackboard system was the target system of the study. Two hundred students participated in the study. There were sixty seven surveys with missing values and therefore were eliminated from the data set, leaving 133 valid responses.

\section{Demographics}

The population was comprised of $36.8 \%$ females and $63.2 \%$ males. $0.8 \%$ of the students were freshman, $24.8 \%$ were sophomores, $21.8 \%$ were juniors, $24.1 \%$ were seniors and $28.6 \%$ were graduate students. The majority of the students (75.2\%) reported high level of computer usage from home. About . 39.1\% of the students reported that they never took a certified computer course and therefore $58.6 \%$ took those certified courses.

\section{Assessing the Measurement Model}

On the other hand, the structural model gives information as to how well the theoretical model predicts the hypothesized paths. Smart PLS provides the squared multiple correlations $\left(\mathrm{R}^{2}\right)$ for each endogenous construct in the model and the path coefficients. $R^{2}$ (table 4 ) indicated the percentage of a construct's variance in the model, whilst the path coefficients indicate the strengths of relationships between constructs [6] Figure 1 shows the results of our PLS model. The figure shows the variance explained $\mathrm{R}^{2}$ in the dependent constructs and the path coefficients $(\beta)$ for the model. All beta coefficients are positive (that is in the expected direction) and statistically significant at $\mathrm{p}<0.05$.

Consistent with Chin [6], bootstrapping (200 resamples) was applied to produce standard errors and t-statistics. This permits us to measure the statistical significance of the path coefficients.

\section{Table $4 \mathrm{R}$ Square}

\begin{tabular}{|l|l|}
\hline & R Square \\
\hline Actual Use & 0.211276 \\
\hline PEOU & 0.00000 \\
\hline PU & 0.229997 \\
\hline Perceived Usage & 0.406649 \\
\hline
\end{tabular}

Table 5 Cronbach’ Alpha

\begin{tabular}{|l|l|}
\hline & Cronbachs Alpha \\
\hline Actual Use & 0.790621 \\
\hline PEOU & 0.635921 \\
\hline PU & 0.787421 \\
\hline Perceived Usage & 0.320070 \\
\hline
\end{tabular}

Table 6 T-Statistics

\begin{tabular}{|l|l|}
\hline & $\begin{array}{l}\text { T Statistics } \\
(\mid \text { O/ STERR })\end{array}$ \\
\hline PEOU -> PU & 6.612774 \\
\hline $\begin{array}{l}\text { PEOU -> Perceived } \\
\text { Usage }\end{array}$ & 1.351791 \\
\hline $\begin{array}{l}\text { PU -> Perceived } \\
\text { Usage }\end{array}$ & 5.909552 \\
\hline $\begin{array}{l}\text { Perceived Usage -> } \\
\text { Actual Use }\end{array}$ & 5.997767 \\
\hline
\end{tabular}

Figure 1 The Structural Model

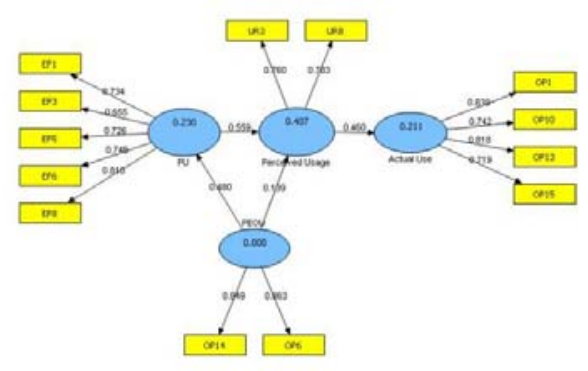

The statistical objective of PLS is to show high $\mathrm{R}^{2}$ and significant t-values, thus rejecting the null hypothesis of no effect. The t-values (table 6) need to be significant to support the hypothesized paths (above 1.96 or 2.56 for alpha levels of .05 and .01 respectively). Only the PEOU and perceived usage path is not supported. Chin [6] also recommends that path coefficients range between 0.20 and 0.30 along with measures that explains $50 \%$ or more of the variance in the latent variable or model. In our case, all the variances were weak. This may be attributed to the fact that other factors (external variables or facilitating conditions) were not included in the model. 


\section{CONCLUSION}

Many institutions are facing declining budgets, enrollments, and revenues that compel them to reconsider their expenses and overheads. Those supportive of online schemes are defended by Brown, Myers, and Roy [5] who think that a sound planned curriculum is crucial to realize success in the classroom or online, the technology is only secondary. Those naturally resisting the online teaching hold to the words of DeLong [10] and Margolis [22] that online teaching demeans the learning experience. Both groups, however perceive technology as an opportunity.

Higher education, like many industries, recognizes the significance of technology for organizational development and survival. Universities are devoting considerable amounts of money, time, and resources into Blackboard to stay competitive. Universities don't know whether students perceive the same level of usage, usefulness and ease of use for all the Blackboard features and if using Blackboard can improve teaching and learning for the students.

This study examined students' perception of Blackboard use through the use of TAM. The results could be used to see how these perceptions might shape institutional decision making for the choice of technology. The choice to convert traditional universities into hybrid or online institutions is crucial.

This article offers additional empirical validation of the power of the TAM model and holds its suitability as an appropriate and reliable measure of technology acceptance in educational settings. This study presents researchers involved in the TAM model with a lasting matter to investigate user actions in these educational setting. It is projected that the TAM model will still be examined in diverse systems evaluations in the states and worldwide.

This study is exploratory as a sample size of 134 may be limiting and may not be representative of all University students in the country. Nonetheless, the findings of this study imply that web-based course supplements are commonly acknowledged,

Our study did not address how the tools affected learning in the context of offline activities.
This study revealed that students will utilize an online educational tool such as blackboard if they see it to be useful to them and if they recognize that the technology is easy to use and supports their needs.

\section{FUTURE WORK}

This study analyzed perceptions of students in the United States. Perception of students internationally may differ as culture impacts the educational delivery system. We intend to extend this study to determine if significant differences exist in an international setting.

An additional area for investigation is to determine if there are significant differences in the perception of usage and ease of use of the other major educational software packages. A cross-sectional analysis to study compare Blackboard results to the use of Web-CT and eCollege,WebMentor, TopClass, Centra is planned.

\section{REFERENCES}

1. Ajzen, I. \& Fishbein, M. (1980). Understanding Attitudes and Predicting Social Behavior. Englewoods Cliffs, NJ: Prentice-Hall, Inc.

2. Atack, L. \& Rankin, J. (2002). A Descriptive Study of Registered Nurses' Experiences with Web-Based Learning. Journal of Advanced Nursing, 40, 457-465.

3. Boettcher, J. (1999). Another Look at the Tower of WWW. Syllabus, October, 50-52.

4. Bose, K. (2003). An eLearning experienceA written analysis based on my experience in an eLearning pilot project. Campus-wide Information System, 20 (5), 193-199.

5. Brown, G., Myers, C. B. and Roy, S. (2003). Formal Course Design and The Student Learning Experience. Journal of Asychronous Learning Network, 7 (3), 6676.

6. Chin, W. (1998). Issues and Opinions on Structural Equation Modeling, MIS Quarterly, 22(1), 7-16.

7. Davis, F. (1986). A Technology Acceptance Model for Empirically Testing New End- 
User Information System: Theory and Results, Doctoral Dissertation, Sloan School of Management, Massachusetts Institute of Technology.

8. Davis, F. (1989, Sep.). Perceived Usefulness, Perceived Ease of Use, and User Acceptance of Information Technology, MIS Quarterly, 319-340.

9. Davis, F. (1993). User Acceptance of Information Technology: System Characteristics, User Perceptions and Behavioral Impacts. International Journal of Machine Studies, 38.

10. Delong, S. E. (1997). The Shroud of Lecturing, First Monday, 2(5) http://www.firstmonday.dk/issues/issue2_5/ delong/index.html

11. Dishaw., M. T. and Strong, D. M. (1999). Extending the Technology Acceptance Model with Task Technology Fit Constructs. Information and Management, 36, 9-21.

12. Driver, M. (2000). Integrating InternetBased Resources Into Classroom Instruction: An Organizational Learning Approach. Journal of Business Education, 1 (Spring), 14-30.

13. Eastman, J. and Swift, C. O. (2001). New horizons in Distance Education: The Online Learner Centered Marketing. Journal of Marketing Education, 23 (3), 25-34.

14. Fornell, C. and Larcker, D. F. (1981). Evaluating Structural Equations Models with Unobservable Variables and Measurement Error, Journal of Marketing Research, 18, 39-50.

15. Janicki, T. \& Steinberg, G. (2003). Evaluation of a Computer-Supported Learning System. Decision Sciences Journal of Innovative Education, 1(2), 203-223.

16. Hwang, Y. and Yi, M. Y. (2002). Predicting the Use of Web-based Information Systems: Intrinsic Motivation and self-efficacy. Eighth Americas Conference on Information Systems, 1076-1081.

17. Karahanna, F., Straub, D.W. and Chervany, N. L. (1999). Information Technology
Adoption Across Time: A Cross-Sectional Comparison of Pre-Adoption and PostAdoption Beliefs, MIS Quarterly, 23(2), $183-$

18. King, K. P. (2001). Educators Revitalize the Classroom "Bulletin Board": A Case Study of the Influence of Online Dialogue on Face-to-Face Classes From an Adult Learning Perspective. Journal of research on Computing in Education, 33 (4), 337-354.

19. Kumar, M., Merriman, J and Long P. (2001). Building Open Frameworks for Education, Educause Review, 36 (6), 80-81.

20. Landry, B. (2003). Students' Reactions to Web-Enhanced Instructional Elements. Phd. Dissertation.

21. Lederer, A. L., Maupin, D. J., Sena, M. P. \& Zhuang, Y. (2000). The Technology Acceptance Model and the World Wide Web. Decision Support Systems, 29 (3), 271-278.

22. Margolis, M.(1998).Brave New Universities, First Monday, 3(5). http://www.firstmonday.dk/issues/issue3_5/ margolis/index.html

23. Meister, D.B. and Compeau, D. R. (2002). Infusion of Innovation Adoption: An Individual Perspective. Annual Conference of the Administrative Sciences Association of Canada (ASAC), Winnipeg, May 25-28.

24. Moon, J.W. and Kim, Y. G. (2001). Extending the TAM For a World-WideWebContext. Information and Management, $38,217-230$.

25. Nunally, J. (1978). Psychometric, 2nd Edition, New York: McGraw Hill.

26. Roed, J. (2003). Language Learner Behavior in a Virtual Environment. Computer Assisted Language Learning, 16, 155-177.

27. Rungtusanatham, M., Ellram, L. M., Siferd, S. P. \& Salik, S. (2004). Toward a Topology of Business Education in the Internet Age. Decision Sciences Journal of Innovative Education, 2(2), 121-152. 
28. Shimizu, K. and Hitt, M. (2004). Strategic Flexibility: Organizational Preparedness to Reverse Ineffective Strategic Decisions. Academy of Management Executive, 19(4), 44-59.

29. Storey, M. A., Phillips, B., Maczewski, M. and Wang, M. (2002). Evaluating the Usability of Web-Based Learning Tools. Educational Technology \& Society, 5(3), 91-100.

30. Szajna, B. (1996). Empirical Evaluation of the Revised Technology Acceptance Model. Management Science, 42 (1), 85-92.

31. Venkatesh, V. (1999). Creation of Favorable User Perceptions : Exploring the Role of Intrinsic Motivation . MIS Quarterly, 23(2), 239-260.

32. Venkatesh, V. and Davis, F. D. (2000). A Theoretical Extension of the Technology Acceptance Model: Four Longitudinal field studies. Management Science, 46(2), 186204. 